\title{
Utility of E-1-(4-Acetamidobenzoyl)-2-Oxirane Carboxylic Acid in Synthesis Some Fused Heterocycles and Spiro Compounds
}

\author{
Sameh. A. Rizk \\ Department of Chemistry, Faculty of Science, University of Ain Shams ,Cairo, Egypt
}

\begin{abstract}
The present work deals with the reaction of 4-(4-Acetyl amino phenyl-4-oxobut-2-enoic acid (1) with hydrogen peroxide afforded oxirane derivative 2.The latter compound was treated with 2-amino-5-aryl-1,3,4-thiadiazole to yield imidazolo[2,1-b]thiadiazole derivatives 4 .The new heterocyclic compounds 4 are used as a key starting materials to synthesize some hetrocycles include pyrrolo-thiadiazolo imidazole, pyridazinone and spiro derivatives. The behavior of the pyridazinone compounds towards different electrophilic and nucleophilic reagents were investigated. The structure of the newly synthesized compounds were elucidated by elemental analysis and spectroscopic data.
\end{abstract}

Keywords 4-Acetamido phenyl-4-oxo-but-2-enoic acid, oxirane,imidazol[2,1-b]thiadiazole, Pyrrolo imidazole,spiro pyrazolo and isoxazolo imidazo thiadiazole,pyridazinone

\section{Introduction}

(E)-4-aryl-4-oxo-2-butenoic acids have been shown that the substitution pattern on the aroyl moiety influences the antiproliferative activity[1] and they have activated double bond,Half-wave reduction potentials (E1/2)[2] display good correlations with Hammett sigma value, attempts to obtain good correlations using frontier orbitals of the molecules.Also,they have emerged the most promising drug candidates[3] which are selective for integrase S-1360[4] and class of Human immunodeficiency virus type1(HIV-1) integrase inhibitors[5] .Spiroindoline[6] and imidazoline[7] derivatives can be evaluated for their binding affinities and antagonistic activities at neuropeptide Y Y5 receptor and good brain penetration. Also, spironolactone is as effective as thiazides in treating mild hypertension without inducing hypokalemia or increased secretion of aldosterone[8,9] and eplerenone ,a specific aldosterone antagonist approved by the food and drug administration ,appears to have a much lower affinity for androgen and progesterone receptors, reduced incidence of sexual disturbances[10] and useful agent in treatment of hepertension and congestive heart failure, treatment of diabetics complication and aldose reductase inhibitors[13]. The most notably ketoconazole[11,12] which have been successful as antifungal agents and when spiroimidazolderivatives[14] was combined with an

* Corresponding author:

Samehrizk2006@gmail.Com. (Sameh. A. Rizk)

Published online at http://journal.sapub.org/ chemistry

Copyright (C) 2011 Scientific \& Academic Publishing. All Rights Reserved tibacterial agent (vancomycin, ciprofloxacin) that observed antagonistic activity results from the competitive binding of the medicine molecules into fungi cells receptors.

3-phenylamino-(substituted phenyl)isoxazolines[15]were evaluated for their in vitro antifungal activity and on the proliferative response of human mononuclear peripheral blood cells to phytohemagglutinin A (PHA)[16].Recently,it reported[17] the synthesized new class of oxadiazoles by cyclization of the terminal carboxylic group of 3-aroyl propionic acids into oxadiazole nucleus that an objective of developing better anti-inflammatory and analgesic agents. Also, pyridazin-2-ylmethyl-2-substituted 1,3,4-oxadiazol e[18] screened for antibacterial, antifungal and antitubercular activity. The effects of $1,3,4$ thiadiazole derivatives on the central nervous system (CNS) of mice were studied[19].Imidazolooxazole derivatives[20] via treatment of imidazolederivatives with oxirane have been tested for antimycobacterial activity .

\section{Results and Discussion}

Reports from our laboratory[21-25] revealed that the $\beta$-aroyl acrylic acids are convenient poly electrophilic reagents in the synthesis of heterocycles, which for the addition reaction of nucleophililes e.g.carbon,nitrogen,sulfur occur exclusively at the $\alpha$-carbon electrophilic center of the carboxy precursors.Morever, reaction with hydrogen peroxide afford oxirane derivative[26]. With the aim of broad ing the synthetic potential of $\beta$-aroyl acrylic acids ,the authors can be reported the behavior of 3-(4- acetylaminobenzoyl) prop -2- enoic acid 1 that was allowed to react 
hydrogen peroxide in the presence of sodium hydroxide afforded the epoxide product E-1-(4-acetylaminobenzoyl) 2 -oxirane carboxylic acid 2 . When the acid 2 is submitted to react with 5-aryl-2-amino-1,3,4-thiadiazole in the presence of few drops of piperidine afforded 2-(5-aryl-1,3,4- thiadiazol-2-yl)amino-3-hydroxy-3-(4-acetylaminobenzoyl) propanoic acid 3, via the $\mathrm{N}$ - alkylation of aminothiadiazole moieties that added to the activated 3-membered heterocycle of the acid 2. The acids 3 undergo spontaneous dehydration to afford imidazolo[2,1-b]thiadiazole derivatives 4 that more thermodynamically stable. (scheme-1)

The different kinds of electrophilic centers in the compounds 4 can be reacted with simply binucleophiles e.g. hydrazine derivatives and hydroxyl amine to afford an im- portant heterocycles and spiro compounds .

The $\alpha$-substituted hydrazone intermediates 5 undergo to internal ring closure via[3+2] instead of [4+2] cyclization process to generate pyrrole derivatives 7 rather than 4,5 -dihydropyridazines $8[27,28]$. The ring closure is promoted in the intermediates 5 by the presence of an acidic hydrogen originally placed in position 4 of the azo-ene system, and promote the thermo chemically allowed[4+2] cyclization to afford the competitive product 9 . Formation of the pyridazinone 9 is due to stability of the bond length and binding energy[29] than isomer 8. Moreover, the authors can be isolated uncommon spiro compounds 10 which have been afforded via the intermediate 6 as outlined in scheme 3 .

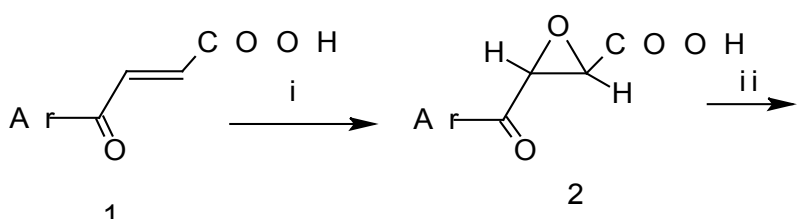

i $\mathrm{LO}_{2} / \mathrm{N}$ a O Hii $\mathrm{H}_{2} \mathrm{~N} \prod_{\mathrm{N}-\mathrm{N}}^{\mathrm{S}} \prod^{\mathrm{R}} / \mathrm{EtOH}$

$\mathrm{Sch}$ e m e 1

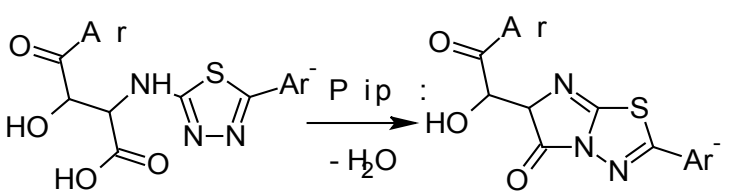

3
4

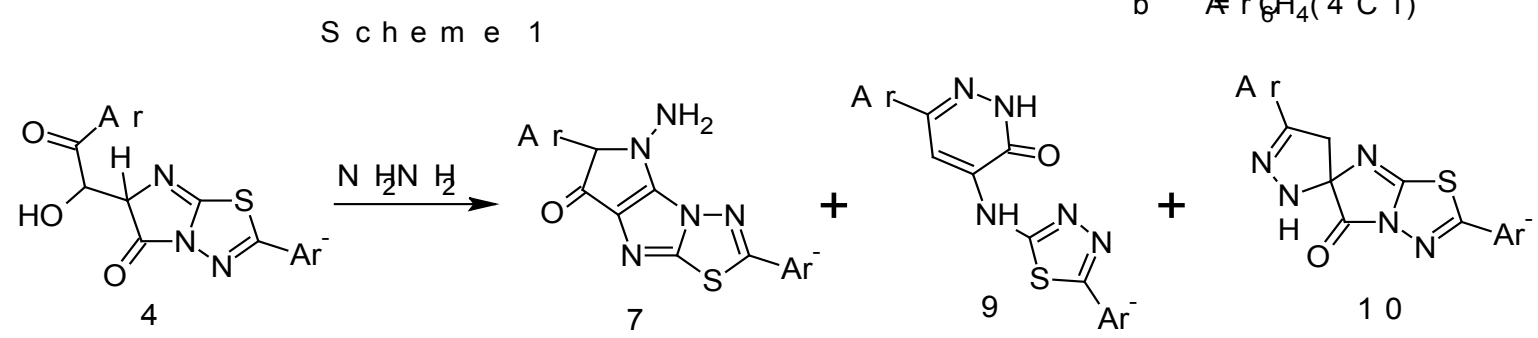

A $r={ }_{6} \bigoplus_{4}\left(4 \quad \mathrm{NHC}\right.$ g) C \& $A^{-}=6 \mathrm{H}_{5} \quad$ b $A^{-}=6 \mathrm{H}_{4}(4 \mathrm{C}$ I)

$S c h$ e $m$ e 2

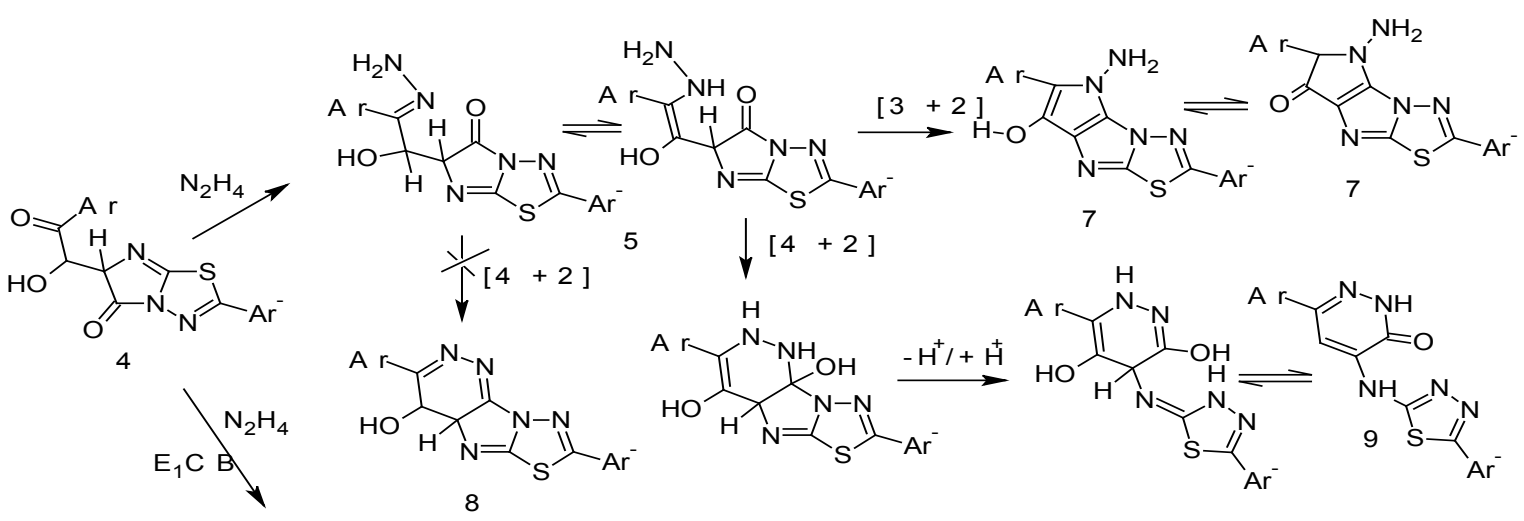

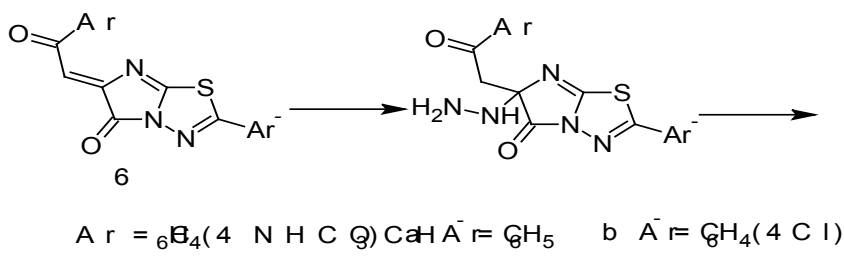

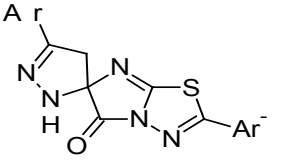

10 


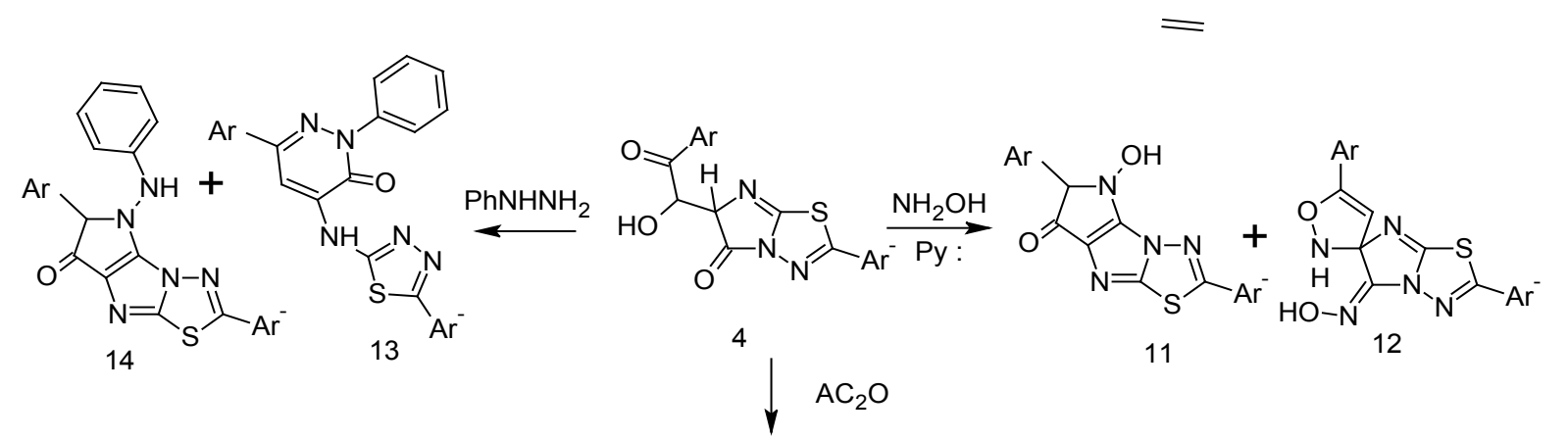

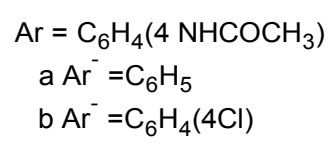<smiles>O=c1oc2nnc(Br)cc2n1-c1nnc(-c2ccccc2)s1</smiles>

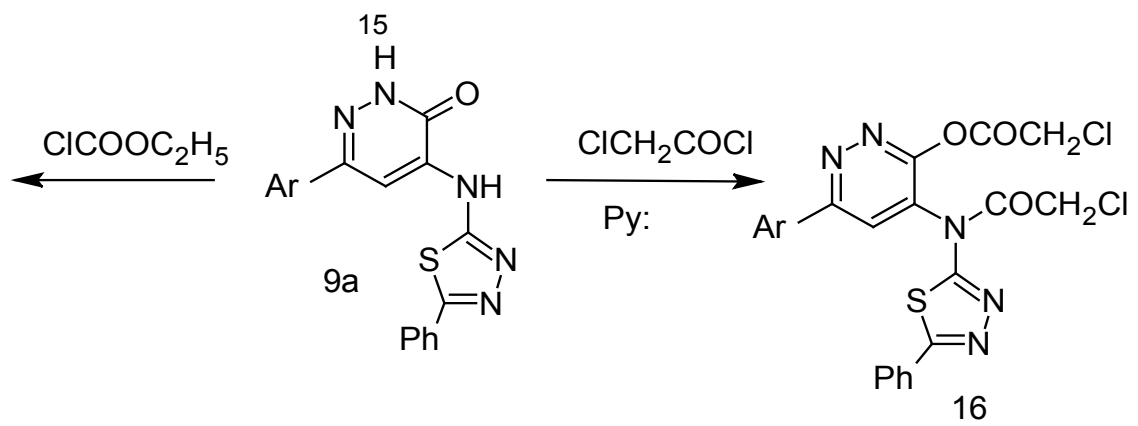

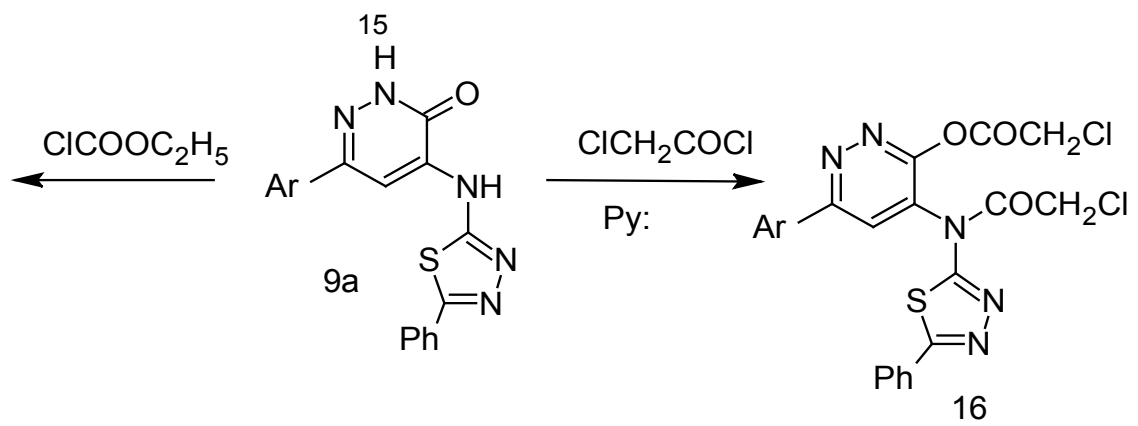

17<smiles>COc1c(Br)oc2c1nc1sc([Al])nn12</smiles>

Scheme 4

15

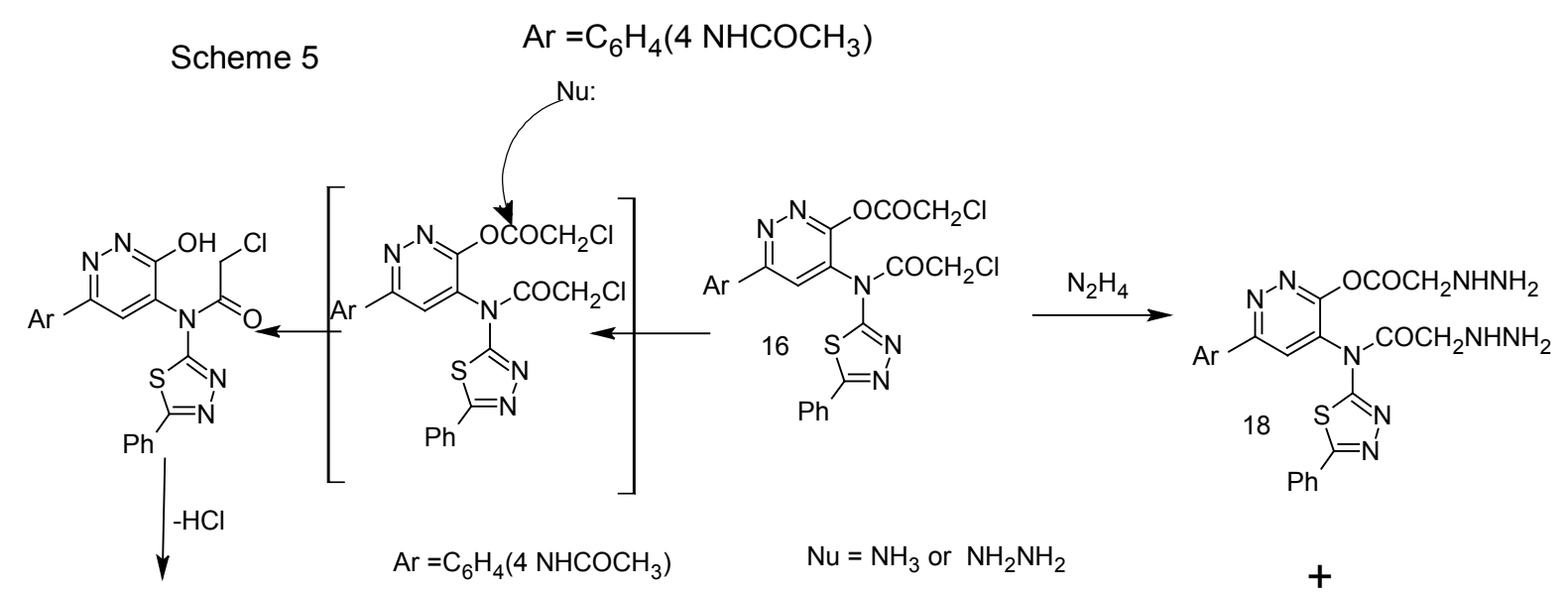<smiles>O=C1COc2nnc(Br)cc2N1c1nnc(-c2ccccc2)s1</smiles>

Scheme 6

Similarity, the compounds 4 were allowed to react with hydroxyl amine in the presence of pyridine afford pyrrole derivatives 11 and spiro isomers 12 (scheme 4). Unsymmetrical hydrazine derivatives also can be affected on regio selectivity in which electronic and steric factors play an important rule. This can be affected on the reaction path that depends on stability of intermediate and the product. Thus, when the compounds 4 were allowed to react with phenyl hydrazine afforded the pyridazinone derivatives 13 and pyrrole derivatives 14 . The latter compounds have low yield due to the steric phenyl group is outweigh intramolecular hydrogen bond and becomes a driving force to regioselective isomer 13. Also, the compounds 4 have been reacted with carbon electrophiles, when 4 were allowed to react with acetic anhydride, they afforded furo[2,3-d] thiadiazolo[3,2-a]imidazole derivatives 15 scheme 4 .

Synthetic $3(2 \mathrm{H})$ pyridazinones are important scaffolds in drug discovery, with many of their analogs being in the treatment of various human pathological states. They were described antihypertensive[30], antibacterial,antifungal[31], 
new azo ligant dye[32], cardiotonic and vasorelaxant activity[33], anti-tumor[34] and Selective cyclin dependent kinase inhibitor[35]. This prompted to continuo[21-24] the preparation of pyridazinone derivatives incorporated with 1,3,4-thiadiazole nucleus in position 4 . Thus, when pyridazinone $9 \mathrm{a}$ was allowed to react with chloro acetyl chloride and ethyl chloro formate, afforded ester 16 and oxazolopyridazine 17 respectively (Scheme 5).

When the chloro ester of pyridazine derivative 15 was allowed to react with hydrazine hydrate and ammonium acetate, it afforded hydrazine derivative 17 and 1,4-oxazino [2,3-c]pyridazine 18 (Scheme 5).

\section{Conclusions}

From the spectroscopic tools, the reaction of isomer 19 possibly takes place via attacking nucleophiles by tetrahedral mechanism followed by ring closure yielded the corresponding 1,4-oxazino[2,3-c]pyridazine 19 (Scheme 6).

The present work is succeeded to synthesis of a series of some important heterocycles and spiro compounds from 4-acetamido phenyl-4-oxo-2-butenoic acid and for the first time,synthesis of pyridazinone derivatives bearing 4-heteryl moiety inside to aromatic substituents in the position 6 that enhances the biological profile many fold than their parent nuclei.

\section{Experimental}

All melting points are uncorrected.and were determined on a stuart electric melting point apparatus.Elemental analyses were carried out at the Microanalytical Center, National Research Center, Cairo, Egypt. By Elementar Viro El Microanalysis IR spectra $(\mathrm{KBr})$ were recorded on infrared spectrometer FT-IR 400D using OMNIC program and are reported frequency of absorption in terms of $\mathrm{cm}-1$ and $\mathrm{H}-\mathrm{NMR}$ spectra recorded on a Bruker spectrophotometer at $400 \mathrm{MHz}$ using TMS as internal standard and withresidual signals of the deuterated solvent $\delta=7.26 \mathrm{ppm}$ for $\mathrm{CDCl} 3$ and $\delta 2.51 \mathrm{ppm}$ for DMSO-d6. C-NMR spectra were recorded on the same

spectrometer at $100 \mathrm{MHz}$ and referenced to solvent signals $\delta=77 \mathrm{ppm}$ for $\mathrm{CDCl} 3$ and $\delta 39.50 \mathrm{ppm}$ for DMSO-d6.DEPT 135 NMR spectroscopy were used where appropriate to aid the assignment of signals in the $\mathrm{H}$ and C-NMR spectra. The mass spectra were recorded on Shimadzu GCMS-QP-1000 EX mass spectrometer at 70 e.v using the electron ionization technique. Homogeneity of all compounds synthesized was checked by TLC.

General Procedure of starting Material in literature[21]. E-1-(4-Acetamidobenzoyl)-2-Oxirane Carboxylic Acid (2)

A solution of 3-(4-acetamidobenzoyl)-prop-2-enoic acid $(2.35 \mathrm{~g} ; 0.01 \mathrm{~mol})$ in acetone $(40 \mathrm{~mL})$ and methyl alcohol $(15$ $\mathrm{mL}$ ) was treated with $8 \%$ aqueous sodium hydroxide $(12 \mathrm{~mL})$ followed by hydrogen peroxide $(30 \%, 5 \mathrm{~mL})$. The reaction mixture was allowed to boil $1 \mathrm{~h}$ and then left over night at room temperature. The crude product was washed by petroleum ether (b.p $40-60^{\circ} \mathrm{C}$ ), and then, crystallized from toluene to give compound 2

Yield 83\%.Mp 172-174 C. IR(KBr) 1645,1687,1710(CO). ${ }^{1} \mathrm{HNMR}$ spectrum $(\mathrm{CDCl} 3): \delta 2.51(\mathrm{~s}, 3 \mathrm{H}, \mathrm{CH} 3), 6.91-6.99$ (2dd, $1 \mathrm{Ha}$ and $1 \mathrm{Hb}$ diastereotopic protons, $\mathrm{J}=14.5$ and 9.2), multiplet at $7.30-7.70$ assigned for $4 \mathrm{ArH}$ aromatic protons, singlet 8.2 a acidic proton which exchanged in D2O and.Anal.Calc. for $\mathrm{C} 12 \mathrm{H} 11 \mathrm{NO} 5$ :C57.38 , H 4.41 ;found: C57.22,H 4.21. MS: m/z 249[M], 205[M- CO2], 163[205 $-\mathrm{COCH} 3]$

\section{Compounds 4}

An equimolar mixture of compound $2(2.5 \mathrm{~g} ; 0.01 \mathrm{~mol})$ and 2-amino-5-aryl-1,3,4-thiadiazole $(0.01 \mathrm{~mol})$ in $50 \mathrm{~mL}$ ethanol. The reaction mixture was refluxed for $3 \mathrm{~h}$. The solid that separated after cool was filtered off,washed by petroleum ether (b.p $40-60^{\circ} \mathrm{C}$ ), dried and then, crystallized from ethanol afford 4

5-[2-(4-acetylaminophenyl)-2-oxo-1-hydroxy]ethyl-4-0xo -2-phenyl imidazolo[2,1-b]1,3,4-thiadiazole (4a)

Yield 74\%.Mp 190-192 C. IR(KBr) $1613(\mathrm{C}=\mathrm{N}), 1650$, 1670, $1685(\mathrm{CO}), 3245(\mathrm{NH}), 3410(\mathrm{OH}) .{ }^{1} \mathrm{HNMR}(\mathrm{DMSO})$ : $\delta 2.5(\mathrm{~s}, 3 \mathrm{H}, \mathrm{CH} 3), 4.11(\mathrm{dd}, 1 \mathrm{Ha},(\mathrm{J}=15.2, \mathrm{~J}=11.2)$ and $1 \mathrm{Hb}$ $(\mathrm{J}=15.2, \mathrm{~J}=11.1)$ sterogenic methine protons), 4.35 (bs, $1 \mathrm{H}$, $\mathrm{OH}$ proton of hydroxyl group), multiplet at $7.44-7.73$ assigned for $9 \mathrm{ArH}$ aromatic protons, singlet 13.2 a acidic $\mathrm{OH}=\mathrm{NH}$ proton which exchanged in $\mathrm{D} 2 \mathrm{O}$ and Anal. Calc. for $\mathrm{C} 20 \mathrm{H} 16 \mathrm{~N} 4 \mathrm{SO} 4$ : $\mathrm{C} 58.82, \mathrm{H} 3.92, \mathrm{~N} \mathrm{13.72}$; found: $\mathrm{C}$ 58.60, H 3.65, N 13.45. MS:m/z 408[M], 377[M-OH+CH3], $285,213,141$.

5-[2-(4-acetylaminophenyl)-2-oxo-1-hydroxy]ethyl-4-oxo -4-chlorophenylimidazolo[2,1-b]1,3,4thiadiazole (4b)

Yield 74\%.Mp 200-202 C. IR(KBr) $1620(\mathrm{C}=\mathrm{N}), 1645$, 1675, 1691(CO), $3245(\mathrm{NH}) .{ }^{1} \mathrm{HNMR}$ (DMSO): $\delta 2.06(\mathrm{~s}, 3 \mathrm{H}$, $\mathrm{CH} 3$ ), 3.50 (bs, $1 \mathrm{H}, \mathrm{OH}$ proton of hydroxyl group), 6.6-6.7 $(2 \mathrm{dd}, 1 \mathrm{Ha},(\mathrm{J}=15.2, \mathrm{~J}=11.2)$ and $1 \mathrm{Hb}(\mathrm{J}=15.2, \mathrm{~J}=11.1)$ sterogenic methine protons), multiplet at $7.44-7.83$ assigned for $8 \mathrm{ArH}$ aromatic protons, singlet 8.2 a acidic $\mathrm{OH}=\mathrm{NH}$ proton which exchanged in $\mathrm{D} 2 \mathrm{O}$ and Anal. Calc. for C20H15N4SClO4: C 54.30, H 3.39, N 12.67; found: C 54.55, H 3.25, N 12.53. MS:m/z 442[M],426[M-OH], 365, 287, 252, 170, 159, 139.

\section{Compounds 7,9,10}

A mixture of $4(0.01 \mathrm{~mol})$ and hydrazine hydrate $(0.01 \mathrm{~mol})$ in ethanol $(50 \mathrm{~mL})$ and was heated under reflux for $5 \mathrm{~h}$. The reaction mixture was allowed to cool and the product was filtered, dried, and were recrystallized from suitable solvent, using the column chromatograph is necessary to separate the compounds 7 and 10 .

2-phenyl-4-amino-5-(4-acetylaminophenyl)-6-oxo- pyrrolo[3,2-d]-1,3,4-thiadiazolo[3,2-a] imidazole (7a)

Yield 35\%.Mp 150-152 C. IR(KBr) 1650,1670 (CO), $3275,3200(\mathrm{NH}), 3400(\mathrm{OH})$. Anal.Calc. for $\mathrm{C} 20 \mathrm{H} 16 \mathrm{~N} 6 \mathrm{SO} 2$ : C 59.40, H 3.96,N 20.79; found: C 59.25, H 3.75, N 20.50

2-(4-chlorophenyl)-4-amino-5-(4-acetylaminophenyl)-6-o xo- pyrrolo[3,2-d]-1,3,4-thiadiazolo[3,2-a]imidazole (7b) 
Yield 35\%.Mp 168-170 C. IR(KBr) 1650,1670 (CO), $3275,3200(\mathrm{NH}), 3400(\mathrm{OH})$. and Anal.Calc. for $\mathrm{C} 20 \mathrm{H} 15 \mathrm{~N} 6 \mathrm{Cl}$ : C 54.79, H 3.42,N 19.17;found: C 54.47 , H 3.21, N 19.03

\section{Compounds 9}

6-(4-acetylaminophenyl)-4-(5-phenyl-1,3,4-thiadiazol-2-y l)amino-2,3-dihydropyridazin-3(2H)one (9a)

Yield 30\%. Mp 203-205 C. IR(KBr) 1640,1687(CO) ,32 $72(\mathrm{NH})$. and Anal.Calc. for C20H16N6SO2 : C 59.40, H 3.96,N 20.79;found: C 59.25 , H 3.75, N $20.60 \mathrm{MS}: \mathrm{m} / \mathrm{z}$ 404[M],360[M-COCH3].

6-(4-acetylaminophenyl)-4-(5-(4-chlorophenyl)-1,3,4-thia diazol-2-yl)amino-2,3-dihydropyridazin-3(2H)one (9b)

Yield 30\%. Mp 220-222 C. IR(KBr) 1627,1687(CO) ,32 $66(\mathrm{NH}) .{ }^{1} \mathrm{HNMR}$ (DMSO-d6): $\delta \quad 2.51(\mathrm{~s}, 3 \mathrm{H}, \mathrm{CH} 3), 6.6$ (bs,3H,NH of amino, acetamido and pyridazinone moiety) 7.26-8.13 (m,9H,Ar-H and pyridazine). Anal.Calc. for C20H15N6ClSO2: C 54.79, H 3.42,N 19.17;found: C 54.52, H 3.22, N 19.00 MS:m/z 438[M],395[M-COCH3].

\section{Compounds 10}

4-phenyl-7-oxo-10-(4-acetylaminophenyl)-spiro[7(2-6)-4] 3-thia-1,5,6,8,9pentazadodecane(10a)

Yield 25\%. Mp 171-175 C. IR(KBr) 1640,1671(CO) ,34 $23(\mathrm{NH}) .{ }^{1} \mathrm{HNMR}$ (DMSO-d6) : $\delta, 2.2(\mathrm{~s}, 2 \mathrm{H}, \mathrm{CH} 2) 2.5(\mathrm{~s}, 3 \mathrm{H}$, CH3) 6.2 (bs,1H,NH) 7.0-7.81 (m,9H,Ar-H), 10.40 (brs, 1H, $\mathrm{NH}$ of acetamido moiety)and Anal.Calc. for $\mathrm{C} 20 \mathrm{H} 16 \mathrm{~N} 6 \mathrm{SO} 2$ : C 59.40, H 3.96,N 20.79;found: C 59.25, H 3.75, N 20.60 MS:m/z 307[M- (aniline radical+H2)],121[PhC=N-NH]. 4-(4-chlorophenyl-7-oxo-10-(4-acetylaminophenyl)-spiro [7(2-6)-4]3-thia-1,5,6,8,9pentazadodecane(10b)

Yield 25\%.Mp 165-168 C. IR(KBr) 1640,1671(CO) ,34 $20(\mathrm{NH})$. Anal.Calc. for $\mathrm{C} 20 \mathrm{H} 15 \mathrm{~N} 6 \mathrm{ClSO} 2$ : C $54.79, \mathrm{H}$ 3.42,N 19.17;found: C 54.52, H 3.22, N 19.00 MS:m/z 404[M-Cl],395[M-COCH3],194[spiro moiety].

\section{Compounds of 11 and 12}

A mixture of 4(0.01 mol) and hydroxyl amine hydrochloride $(1.03 \mathrm{~g} ; 0.015 \mathrm{~mol})$ in boiling pyridine $(50 \mathrm{~mL})$ and was heated under reflux for $6 \mathrm{~h}$. The reaction mixture was allowed to cool, pour into ice $/ \mathrm{HCl}$ and the product was filtered, dried, and were recrystallized from toluene afford 11 and ethanol afford 12

2-phenyl-4-hydroxy-5-(4-acetylaminophenyl)-6-oxopyrrolo[3,2-d]-1,3,4-thiadiazolo[3,2-a] imidazole (11a)

Yield 40\%.Mp 165-167 C. IR(KBr) 1650,1683 (CO), $3245(\mathrm{NH}), 3450(\mathrm{OH})$. and Anal.Calc. for C20H15N5SO3 : C 59.25, H 3.70,N 17.28;found: C 59.00 , H 3.45, N 17.00 MS:m/z 403[M-H2],362[M-COCH3],268[361-phenol moiety].

2-(4-chlorophenyl)-4-hydroxy-5-(4-acetylaminophenyl)6-oxo- pyrrolo[3,2-d]-1,3,4-thiadiazolo[3,2-a]imidazole (11b)

Yield 45\%.Mp 168-170 C. IR(KBr) 1650,1670 (CO), 3275(NH),3450 (OH). and Anal.Calc. for C20H14N5ClSO3 : C 54.66, H 3.19,N 15.94;found: C 54.36, H 3.02, N 15.68 4-phenyl-7-hydroxyimino-10-(4-acetylaminophenyl)-spir o[7(2-6)-4]9-oxa-3-thia-1,5,6,8, tetrazadodecane(12a)

Yield $35 \%$.Mp 197-200 C. IR(KBr) 1630(CO) ,3425
$(\mathrm{NH}) .{ }^{1} \mathrm{HNMR}$ (DMSO-d6) $: \quad \delta \quad 2.23(\mathrm{~s}, 3 \mathrm{H}, \mathrm{CH} 3), 4.29$ $\mathrm{S}_{\mathrm{B}}, 2 \mathrm{H}, \mathrm{OH}$ and $\mathrm{NH}$ groups) $7.00-7.70(\mathrm{~m}, 10 \mathrm{H}, \mathrm{Ar}-\mathrm{H}), 12.70$ (brs, $1 \mathrm{H}, \mathrm{NH}$ of acetamido moiety) and Anal.Calc. for C20H16N6SO3 : C 57.14, H 3.80,N 20.00;found: C 57.00, H 3.55, N 19.72 .

4-(4-chlorophenyl-7-hydroxyimino-10-(4-acetylaminoph enyl)-spiro[7(2-6)-4]9-oxa-3-thia-1,5,6,8, tetrazado decan e(12b)

Yield 35\%.Mp 192-195 C. IR(KBr) 1631 (CO) ,3271 (NH). Anal.Calc. for $\mathrm{C} 20 \mathrm{H} 15 \mathrm{~N} 6 \mathrm{ClSO} 3$ : C 52.86, H 3.30,N 18.50;found: C 54.52 , H 3.16, N 18.25 MS:m/z 454[M],34 3 [M-chlorobenzene].

\section{Compounds 13:}

A mixture of $4(0.01 \mathrm{~mol})$ and phenyl hydrazine $(0.01 \mathrm{~mol})$ in ethanol $(40 \mathrm{~mL})$ and was heated under reflux for $5 \mathrm{~h}$. The reaction mixture was allowed to cool and the separated product was filtered, dried and were recrystallized from benzene/toluene afford 14 and ethanol afford 13 .

2-phenyl-4-(5-phenyl-1,3,4-thiadiazol-2-yl)amino-6-(4-ac etylaminophenyl)-2,3-dihydropyridazin-3(2H)one (13a)

Yield 40\%. Mp 212-214 C. IR(KBr) 1640,1687 (CO) ,31 $70(\mathrm{NH})$. and Anal.Calc. for C26H20N6SO2 : C 65.00, $\mathrm{H}$ 4.16,N 17.50;found: C 64.70, H 4.00, N 17.36 .

2-phenyl-4-(5-(4-chlorophenyl)-1,3,4-thiadiazol-2-yl)ami no-6-(4-acetylaminophenyl)-2,3-dihydro-pyridazin-3(2H )one (13b)

Yield 45\%. Mp 230-232 C. IR(KBr) 1632,1721 (CO) ,32 $20(\mathrm{NH})$. Anal.Calc. for $\mathrm{C} 26 \mathrm{H} 19 \mathrm{~N} 6 \mathrm{ClSO} 2$ : C $60.70, \mathrm{H}$ 3.69,N 16.34;found: C 60.44, H 3.32, N 16.10 .

2-phenyl-4-phenylamino-5-(4-acetylaminophenyl)-6-oxopyrrolo[3,2-d]-1,3,4-thiadiazolo-[3,2-a] imidazole (14a)

Yield 35\%.Mp 170-172 C. IR(KBr) 1650,1670 (CO), $3275,3200(\mathrm{NH}), 3400(\mathrm{OH})$. and Anal.Calc. for $\mathrm{C} 26 \mathrm{H} 20 \mathrm{~N} 6$ $\mathrm{SO} 2$ : C $65.00, \mathrm{H} 4.16, \mathrm{~N}$ 17.50;found: C $65.00, \mathrm{H} 4.10, \mathrm{~N}$ 17.26

2-(4-chlorophenyl)-4-phenylamino-5-(4-acetylaminophe nyl)-6-oxo- pyrrolo [3,2-d]-1,3,4-thiadiazolo[3,2-a]imidaz ole (14b)

Yield 35\%.Mp 190-191 C. IR(KBr) 1650,1670 (CO), 3275,3200 (NH),3400 (OH). and Anal.Calc. for C26H19N6 ClSO2 C 60.70, H 3.69,N 16.34;found: C 60.44, H 3.32, N 16.10

\section{Compounds 15a-b}

A mixture of 4(0.01 mol) and acetic anhydride $(9.4$ $\mathrm{mL}, 0.1 \mathrm{~mol})$ and then refluxed on water bath for $2 \mathrm{~h}$. The excess acetic anhydride was removed by distillation and the separated product was filtered,dried and were recrystallized from mix toluene-ethanol

2-acetoxy-3-(4-acetylaminophenyl)-6-phenyl-furo[3,2-d]1,3,4-thiadiazolo[3,2-a] imidazole (15a)

Yield 74\%.Mp 150-152 C. IR(KBr) $1613(\mathrm{C}=\mathrm{N}), 1650$, 1764, $1850(\mathrm{CO}), 3154(\mathrm{NH}), 3436(\mathrm{OH}) .{ }^{1} \mathrm{HNMR}$ (DMSO): $\delta 2.22(\mathrm{~s}, 3 \mathrm{H}, \mathrm{CH} 3), 2.50(\mathrm{~s}, 3 \mathrm{H}, \mathrm{CH} 3 \mathrm{COO})$, multiplet at $7.50-$ 7.90 assigned for $9 \mathrm{ArH}$ aromatic protons, singlet 12.67 a acidic $\mathrm{OH}=\mathrm{NH}$ proton which exchanged in $\mathrm{D} 2 \mathrm{O}$ and Anal.Calc. for C22H16N4SO4: C 61.11 , H 3.70,N 12.96;found: C 60.90, H 3.47, N 12.77. 
2-acetoxy-3-(4-acetylaminophenyl)-6-(4-chlorophenyl)-f uro[3,2-d]-1,3,4-thiadiazolo[3,2-a]imidazole(15b)

Yield 74\%. Mp 144-146 C. IR(KBr) $1620(\mathrm{C}=\mathrm{N}), 1645,1$ 767,1850 (CO), $3157(\mathrm{NH}) 3438(\mathrm{OH}) .{ }^{1} \mathrm{HNMR}$ (DMSO): $\delta$ $2.21(\mathrm{~s}, 6 \mathrm{H}, \mathrm{CH} 3 \mathrm{CONH} \mathrm{CH} 3 \mathrm{COO})$, multiplet at $7.51-7.94$ assigned for $8 \mathrm{ArH}$ aromatic protons, singlet 12.57 a acidic $\mathrm{OH}=\mathrm{NH}$ proton which exchanged in $\mathrm{D} 2 \mathrm{O}$ and Anal.Calc. for C22H15N4SClO4 : C 56.65 , H 3.21,N 12.00;found: C $56.40, \mathrm{H} 3.00, \mathrm{~N} 11.77$.

\section{3-chloroacetoxy6-(4-acetylaminophenyl)-4-(5-phenyl-1,3} ,4-thiadiazol-2-yl)chloroacetylaminopyridazine (16)

An equimolar mixture of compound $9 \mathrm{a}(2.0 \mathrm{~g} ; 5 \mathrm{mmol})$ and chloroacetylchloride $(1.7 \mathrm{~mL}, 0.015 \mathrm{~mol})$ in $50 \mathrm{~mL}$ dry pyridine. The reaction mixture was refluxed for $3 \mathrm{~h}$. The reaction mixture poured into ice/ $\mathrm{HCl}$ and the solid that separated was filtered off, dried and then, crystallized from ethanol .

Yield 45\%. Mp 132-134 C. IR(KBr) 1660,1722,1781 (CO), $3317(\mathrm{NH})$. and Anal.Calc. for C24H18N6SCl2O4 : C 51.80 , H 3.23,N 15.10;found: C 51.84 , H 3.13, N 15.40 MS:m/z 485[M-2Cl],380[M-OCOCH2CO moiety] ,360[M-( $\mathrm{CH} 3 \mathrm{CO}+2 \mathrm{ClCH} 2 \mathrm{CO})]$.

\section{2-oxo-3-(5-phenyl-1,3,4-thiadiazol-2-yl)}

-5-(4-acetylaminophenyl)-)oxazolo[5,4-c]pyridazine (17)

An equimolar mixture of compound $9 \mathrm{a}(2.0 \mathrm{~g} ; 5 \mathrm{mmol})$ and ethylchloroformate $(1.4 \mathrm{~mL}, 0.015 \mathrm{~mol})$ in $50 \mathrm{~mL}$ dry pyridine. The reaction mixture was refluxed for $3 \mathrm{~h}$. The reaction mixture poured into ice/ $\mathrm{HCl}$ and the solid that separated was filtered off, dried and then, crystallized from ethanol .

Yield 75\%. Mp 142-144 C. IR(KBr) 1660,1725(CO) ,31 $60(\mathrm{NH})$. and Anal.Calc. for C21H14N6SO3 : C $58.60, \mathrm{H}$ 3.25,N 19.53;found: C 58.38 , H 3.17, N 19.30 MS:m/z $430[\mathrm{M}]$.

2-oxo-4-(5-phenyl-1,3,4-thiadiazol-2-yl)-6-(4-acetylamin ophenyl)-)1,2,3,4tetrahydro1,4-oxazino[2,3-c] pyridazine (18)

Yield 35\%. Mp 190-192 C. IR(KBr) 1650,1723 (CO), 3320,3188 (NH2,NH). ${ }^{1} \mathrm{HNMR}$ (DMSO-d6) : $\delta$ 2.08(s,3H, $\mathrm{CH} 3), 4.13-4.17(\mathrm{~s}, 4 \mathrm{H}, 2 \mathrm{CH} 2-\mathrm{N}) 6.72-6.76(\mathrm{~m}, 6 \mathrm{H}, 2 \mathrm{NHNH} 2)$, 7.46-7.92 (m,10H,Ar-H and pyridazine), 11.36 (brs, $1 \mathrm{H}, \mathrm{NH}$ of acetamido moiety) and Anal.Calc. for C24H24N10SO4 : C 52.55, H 4.37,N 25.54;found: C 52.30, H 4.16, N 25.00 3-oxo-4-(5-phenyl-1,3,4-thiadiazol-2-yl)-6-(4-acetylamin ophenyl)-)1,2,3,4tetrahydro1,4-oxazino[2,3-c] pyridazine (19)

An equimolar mixture of compound $16(2.75 \mathrm{~g} ; 5 \mathrm{mmol})$ and hydrazine hydrate $(1.7 \mathrm{~mL}, 0.015 \mathrm{~mol})$ and /or ammonium acetate $(1.2 \mathrm{~g} ; 0.015 \mathrm{~mol})$ in $50 \mathrm{~mL}$ dry pyridine. The reaction mixture was refluxed for $3 \mathrm{~h}$. The reaction mixture poured into ice $/ \mathrm{HCl}$ and the solid that separated was filtered off, dried and then, crystallized from ethanol .

Yield $67 \%$.Mp 168-170 C. IR(KBr) 1644,1708,1729 (CO) ,3177 (NH). ${ }^{1} \mathrm{HNMR}(\mathrm{DMSO}-\mathrm{d} 6): \delta 2.2(\mathrm{~s}, 3 \mathrm{H}, \mathrm{CH} 3$ ), $4.2(\mathrm{~s}, 2 \mathrm{H}, \mathrm{CH} 2-\mathrm{N}), 7.43-7.81 \quad(\mathrm{~m}, 10 \mathrm{H}, \mathrm{Ar}-\mathrm{H}$ and pyridazine), 11.59 (brs, $1 \mathrm{H}, \mathrm{NH}$ of acetamido moiety) and Anal.Calc. for C22H16N6SO3 : C 59.45, H 3.60,N 18.91;found: C 59.28, H 3.43, N 18.72 MS:m/z 444[M].

\section{REFERENCES}

[1] Juranic, Z.; Stevovic, Lj.; Drakulic, B.; Stanojkovic, T.; Radulovic, S.; Juranic, I. O. J. Serb. Chem. Soc. 1999,64,505 $-512$

[2] Ferenc T. Pastor, Branko J. Drakulic Linear free energy relationships of half-wave reduction potentials of (E)-4-aryl4-oxo-2-butenoic acids Tetrahedron Letters 51 (2010) $734-738$

[3] Neamati, N. Expert. Opin. Ther. Pat. 2002, 12, 709

[4] Billich, A. Curr. Opin. Investig. Drugs 2003, 4, 206

[5] Cedric Maurin, Fabrice Bailly and Philippe Cotelle Improved preparation and structural investigation of -aryl-4- oxo-2-hyd roxy-2-butenoic acids and methyl esters Tetrahedron 60 (2004) 6479-6486

[6] Toshihiro Sakamoto, Minoru Moriya, Yuji Haga, Toshiyuki Takahashi, Takunobu Shibata, Osamu Okamoto, Katsumasa Nonoshita, Hidefumi Kitazawa, Masayasu Hidaka, Akira Gomori, Hisashi Iwaasa, Akane Ishihara, Akio Kanatani, Takehiro Fukami, Ying-Duo Gao, Douglas J. MacNeil, Lihu Yang Identification of novel and orally active spiroindoline NPY Y5 receptor antagonists Bioorganic \& Medicinal Chemistry Letters 19 (2009) 1564-1568

[7] Nagaaki Sato, Makoto Jitsuoka, Shiho Ishikawa, Keita Nagai, Hiroyasu Tsuge, Makoto Ando, Osamu Okamoto, Hisashi Iwaasa, Akira Gomori, Akane Ishihara, Akio Kanatani, Takehiro Fukami,Discovery of substituted 2,4,4- triarylimidazoline derivatives as potent and selective neuropeptide Y Y5 receptor antagonists;Bioorganic \& Medicinal Chemistry Letters 19 (2009) 1670-1674

[8] Laragh,J.H.;and Sealey,J.E.;Hypertension 37(part 2),806. 2001

[9] Laragh,J.H.;Am.J.Hypertens. 14,84,2001

[10] Epstein,M.;Am,J.Kidney Dis.37,677,2001

[11] Korting H.C., Schaller M.: Hautarzt52, 91,2001

[12] Hurwitz A., Ruhl C.E., Kimler B.F., Topp E.M., Mayo M.S.: J. Clin. Pharmacol.: 43, 996 (2003

[13] Shuichi Miyamoto;Molecular modeling and structure based drug discovery studies of aldose reductase inhibitors;Chem-Bio informatics Journal 2002,2(3) 74-85

[14] Dariusz A. P., Andrzej. M. B., Agnieszk E. L., Bohdan J. S. Jerzy K; SYNTHESIS OF 1-\{4-[4- (ADAMANT -1-YL)PH ENOXYMETHYL]- 2-(4-BROMOPHENYL)-1,3DIOXOLAN-2-YLMETHYL $\}$ IMIDAZOLE WITH EXPECTED ANTIFUNGAL AND ANTIBACTERIAL ACTIVITY; Acta Poloniae Pharmaceutica ñ Drug Research, Vol. 64 No. 6 pp. 535 ñ540, 2007

[15] Prabodh C. S. , Sunil V. S. , Sandeep J. , Dalbir S., Bhojraj S. SYNTHESIS OF SOME NEW ISOXAZOLINE DERIVATIVES AS POSSIBLE ANTI-CANDIDA AGENTS,Acta Poloniae Pharmaceutica ñ Drug Research, Vol. 66 No. 1 pp. 101ñ104, 2009

[16] a-Marcin M. , Michal Z., Magdalena T. , Stanislaw R. 
SYNTHESIS, IMMUNOLOGICAL ACTIVITY AND COMPUTATIONAL STUDY OF

5-AMINO-3-METHYL-4-ISOXAZOLECARBOXYLIC

ACID SEMICARBAZIDES AND THIOSEMICARBAZIDES; Acta Poloniae Pharmaceutica ñ Drug Research, Vol. 65 No. 5 pp. 543ñ549, 2008.b-MARCIN M•CZY-SKI, MICHA£ ZIMECKI ,STANIS£AW RYNG, NEW CLASS OF ISOXAZOLE DERIVATIVES: THE M 1-9 SERIESOF COMPOUNDS WITH IMMUNOTROPIC ACTIVITY, Acta Poloniae Pharmaceutica ñ Drug Research, Vol. 65 No. 2 pp. 241ก̃ 244,2008

[17] Asif H.,Mohammed S., Priyanka A.4)-3]-2 - CHLORO/ETHYL PHENYL)PROPAN -3-ONE]-5- (SUBSTITUTED PHENYL)-1,3,4-OXADIAZOLES: SYNTHESIS AND BIOLOGICAL EVAlUATION; Acta Poloniae Pharmaceutica ñ Drug Research, Vol. 65 No. 5 pp. 527ñ534, 2008

[18] Mojahidul I., Anees A Siddioui , Ramadoss R. , Afroz B. ,Sunil G. SYNTHESIS AND ANTIMICROBIAL ACTIVITY OF SOME NOVEL OXADIAZOLE DERIVATIVES;Acta Poloniae Pharmaceutica ñ Drug Research, Vol. 65 No. 4 pp. $441 \tilde{n} 447,2008$

[19] Nazar T. , Maria D. , Ewa J.J. CYCLIZATION OF THIOSEMICARBAZIDE DERIVATIVES OF 5-ARYLIDE NE-2,4-DIOXOTHIAZOLIDINE-3-ACETIC ACIDS TO1,3,4-THIADIAZOLES AND THEIR PHARMACOLOGICAL PROPERTIES, Acta Poloniae Pharmaceutica ñ Drug Research, Vol. 64 No. 3 pp. 227ñ231, 2007

[20] Justyna Ø. , Dorota O., Zofia Z., Ewa A., Lucjusz Z.; SYNTHESIS OF 2,3-DIHYDRO-7-NITROIMIDAZO[5,1-b ]OXAZOLE AS POTENTIAL TUBERCULOSTATIC AGENTS, Acta Poloniae Pharmaceutica ñ Drug Research, Vol. 65 No. 2 pp. $229 \tilde{n} 233,2008$

[21] S.A.Rizk , M.A.El-Hashash , M.M.Aburzeza ; 1,4-Arylation of $\beta$-(4-acetylaminobenzoyl)acrylic Acid with Activated Aromatic Hydrocarbons under Fridel-Crafts Conditions and Some Studies with the Products.Egypt.J.Chem. 2011, 54,1,

[22] Sameh A.Rizk, Maher A. El-Hashash; 2-(3,4-dimethylpheny 1-[3,4-dichloro (or 3,4-dimethyl) benzoyl) -propanoic acids as Precursors in the Synthesis of Some Heterocyclic Compounds Egypt.J.Chem. 2011,54,5.

[23] Sameh. A. Rizk, Maher.A.EL-Hashash and Moktar. M.Abur zeza; Utility of p-Acetamidobenzoyl Prop-2enoic Acid in the Synthesis of New $\alpha$-Amino Acids and Using them as Building Blocks in Heterocyclic Synthesis Egypt.J.Chem. $2011,54,3$

[24] Rizk,S.A;El-Hashash,M.A.;Mostafa,K.K.; Utility of $\beta$-Aroyl
Acrylic acid in Heterocyclic Synthesis.Egypt, J. Chem. 2008,51 (5) 116-121.

[25] El-Kadi M.,El-Hashash M.A.,Sayed M.;Action of Hydrazine,Amine and Thiourea upon 3-(4-chloro-3-methyl)benzoyl acrylic acid;Revue Roumaine de Chimie 26 8,1161-1167 1981

[26] El-Hashash M.A.,El-Kady M.,Some Reactions of 3-Aroyl Acrylic Acid Epoxides;Revue Roumaine de Chimie 23 11-12,1581-1588 1978

[27] (a) Attanasi, O. A.; Filippone, P. Synlett 1997, 1128-1140; (b) Attanasi, O. A.; De Crescentini, L.; Filippone, P.; Mantellini, F.; Santeusanio, S. ARKIVOC 2002, xi 274-292

[28] Orazio A. Attanasi, Stefano Berretta, Lucia De Crescentini, Gianfranco Favi Fabio Mantellini Amalija Golobic; Synthesis of new cycloalkenyliden-pyrroles by domino reaction; Tetrahedron 65 (2009) 2290-2297

[29] Yong-Jin Yoon, In-Sun Koo, and Jong Keun Park; Characteristic Effects of 4,5-Disubstituted Pyridazin-3-one Derivatives with Various Functional Groups: Ab initio Study; Bull. Korean Chem. Soc. 2007, Vol. 28, No. 8

[30] Anees A. Siddiqui, Ravinesh Mishra, Mohammad Shaharyar;Synthesis, characterization and antihypertensive activity of pyridazinone derivatives;European Journal of Medicinal Chemistry 45 (2010) 2283-2290

[31] Roxana M. Butnariu, Ionel I. Mangalagiu; New pyridazine derivatives: Synthesis, chemistry and biological activity; Bioorganic \& Medicinal Chemistry 17 (2009) 2823-2829

[32] Hamid Khanmohammadi , Maryam Darvishpour; New azo ligands containing azomethine groups in the pyridazine-based chain; Dyes and Pigments 81 (2009) 167-173 :

[33] Dinesh Kumar, Rosalia Carron, Carmen D.Calle, Dharam P. Jindal, Ranju Bansal; - Synthesis and evaluation of 2-substituted-6-phenyl-4,5-dihydropyridazin-3(2H)-ones Acta Pharm. 58 (2008) 393-405 as potent inodilators;

[34] Norbert H. and Eddy S.;1,5- Dimethyl-6H-pyridazino [4,5-b] carbazole, a 3-Aza Bioisoster of the Antitumor Alkaloid Olivacine Chem. Pharm. Bull. 50(11) 1479-1483 (2002)

[35] Kirk L. Stevens, Michael J. Reno , Jennifer B. Alberti , Daniel J. Price, Laurie S. Kane-Carson ,Victoria B. Knick, Lisa M. Shewchuk, Anne M. Hassell, James M. Veal,Stephen T. Davis ,Robert J. Griffin , Michael R. Peel ;Synthesis and evaluation of pyrazolo[1,5-b]pyridazines as selective cyclin dependent kinase inhibitorsBioorganic \& Medicinal Chemistry Letters 18 (2008) 5758-5762 